$$
\text { CONF-970315--3 }
$$

\title{
CLADDING METALLURGY AND FRACTURE BEHAVIOR DURING REACTIVITY-INITIATED ACCIDENTS AT HIGH BURNUP*
}

H. M. Chung and T. F. Kassner

ANL/ET/CP- $/$ I $/ 31397$ Argonne National Laboratory

Argonne, IL 60439

\section{SCEIVED \\ APR 141997 \\ OSTI}

\begin{abstract}
The submitted manuscript has been created by the University of Chicago as Operator of Argonne National Laboratory ("Argonne") under Contract No. W-31-109-ENG38 with the U.S. Department of Energy. The U.S. Government retains for itself, and others acting on its behalf, a paid-up, nonexclusive, irrevocable worldwide

license in

works, distribute copies to the public, and perform

publicly and display publicly, by or on behalf of the

Government
\end{abstract}

December 1996

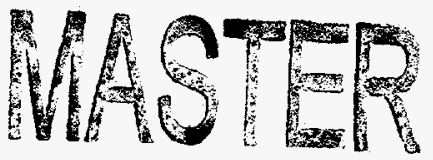

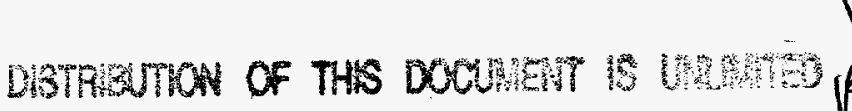

To be published in Proc. International Topical Meeting on Light Water Reactor Fuel Performance, March 2-6, 1997, Portland, Oregon.

*Work supported by the Office of Nuclear Regulatory Research, U.S. Nuclear Regulatory Commission. 


\section{DISCLAIMER}

This report was prepared as an account of work sponsored by an agency of the United States Government. Neither the United States Government nor any agency thereof, nor any of their employees, make any warranty, express or implied, or assumes any legal liability or responsibility for the accuracy, completeness, or usefulness of any information, apparatus, product, or process disclosed, or represents that its use would not infringe privately owned rights. Reference herein to any specific commercial product, process, or service by trade name, trademark, manufacturer, or otherwise does not necessarily constitute or imply its endorsement, recommendation, or favoring by the United States Government or any agency thereof. The views and opinions of authors expressed herein do not necessarily state or reflect those of the United States Government or any agency thereof. 


\section{DISCLAMER}

Portions of this document may be illegible in electronic image products Images are produced from the best available original document. 


\section{CLADDING METALLURGY AND FRACTURE BEHAVIOR DURING REACTIVITY-INITIATED ACCIDENTS AT HIGH BURNUP*}

\author{
H. M. Chung \\ Argonne National Laboratory \\ Argonne, Illinois 60439 \\ Tel. 630-252-5111 \\ Fax 630-252-3604
}

T. F. Kassner

Argonne National Laboratory

Argonne, Illinois 60439

Tel. $630-252-5191$

Fax 630-252-3604

\begin{abstract}
High-burnup fuel failure during a reactivity-initiated accident has been the subject of safety-related concern. Because of wide variations in metallurgical and simulation test conditions, it has been difficult to understand the complex failure behavior from major tests in the NSRR and CABRI reactors. In this paper, a failure model based on fracture toughness and microstructural characteristics is proposed in which fracture toughness of high-burnup cladding is assumed to be sensitive to temperature and exhibit ductile-brittle transition phenomena similar to those of irradiated bodycentered-cubic alloys. Significant effects of temperature and shape of the pulse are predicted when a simulated test is conducted near the material's transition temperature. Temperature dependence of fracture toughness is, in turn, sensitive to cladding microstructure such as density, distribution, and orientation of hydrides, oxygen distribution in the metallic phase, and irradiation-induced damage. Because all of these factors are strongly influenced by corrosion, the key parameters that influence susceptibility to failure are oxide layer thickness and hydriding behavior. Therefore, fuel failure is predicted to be strongly dependent on cladding axial location, as well as on burnup.
\end{abstract}

\section{INTRODUCTION}

During the past several years, safetyrelated issues associated with the performance of high-burnup LWR fuels during a reactivity-initiated accident (RIA)

\footnotetext{
*Work supported by the Office of Nuclear Regulatory Research, U.S. Nuclear Regulatory Commission.
}

have been the subject of extensive investigations. Beginning in early 1990s, important pulse tests have been conducted in several test reactors under simulated RIA conditions, and results of these tests have been evaluated relative to the current licensing acceptance criteria for fuel behavior during RIA. In some of the well-known tests conducted on PWR fuels with burnup of $\approx 45-63 \mathrm{GWd} / t$, highSn Zircaloy-4 cladding failed when the radially averaged fuel enthalpy was surprisingly low, i.e., only $\approx 30-70 \mathrm{cal} / \mathrm{g}$ (Fig. 1).1,2 Because of these results, fresh attention was also focused on a test conducted in the 1970s in the SPERT reactor in which a fuel with a burnup of $\approx 32 \mathrm{GWd} / \mathrm{t}$ failed at $\approx 85 \mathrm{cal} / \mathrm{g}$. The energy deposits of $<100 \mathrm{cal} / \mathrm{g}$ of these failures are significantly lower than the threshold energy currently imposed by regulatory authorities to prevent cladding melting, fragmentation, and fuel dispersal, e.g., 280 $\mathrm{cal} / \mathrm{g}$ in the U.S., $230 \mathrm{cal} / \mathrm{g}$ in Japan, and 225 and $200 \mathrm{cal} / \mathrm{g}$ for fresh and irradiated fuel, respectively, in France.

The conditions of these simulated tests in the SPERT, CABRI, and NSRR reactors were, however, significantly different from those of an RIA in a PWR, e.g., fuel cladding environment (nonpressurized water or liquid sodium), pulse shape (characteristic pulse half width $\approx 5-10 \mathrm{~ms}$ vs. $\approx 60-70 \mathrm{~ms}$ estimated for an RIA), and rod mechanical constraints. Pretest metallurgical conditions of the cladding were also quite varied, even when the test specimens were sectioned from the same mother rod, i.e., oxide layer thickness, oxide spallation, thickness of the remaining metallic Zircaloy-4, hydride morphology and distribution, and hydrogen and oxygen content of the metallic phase. 


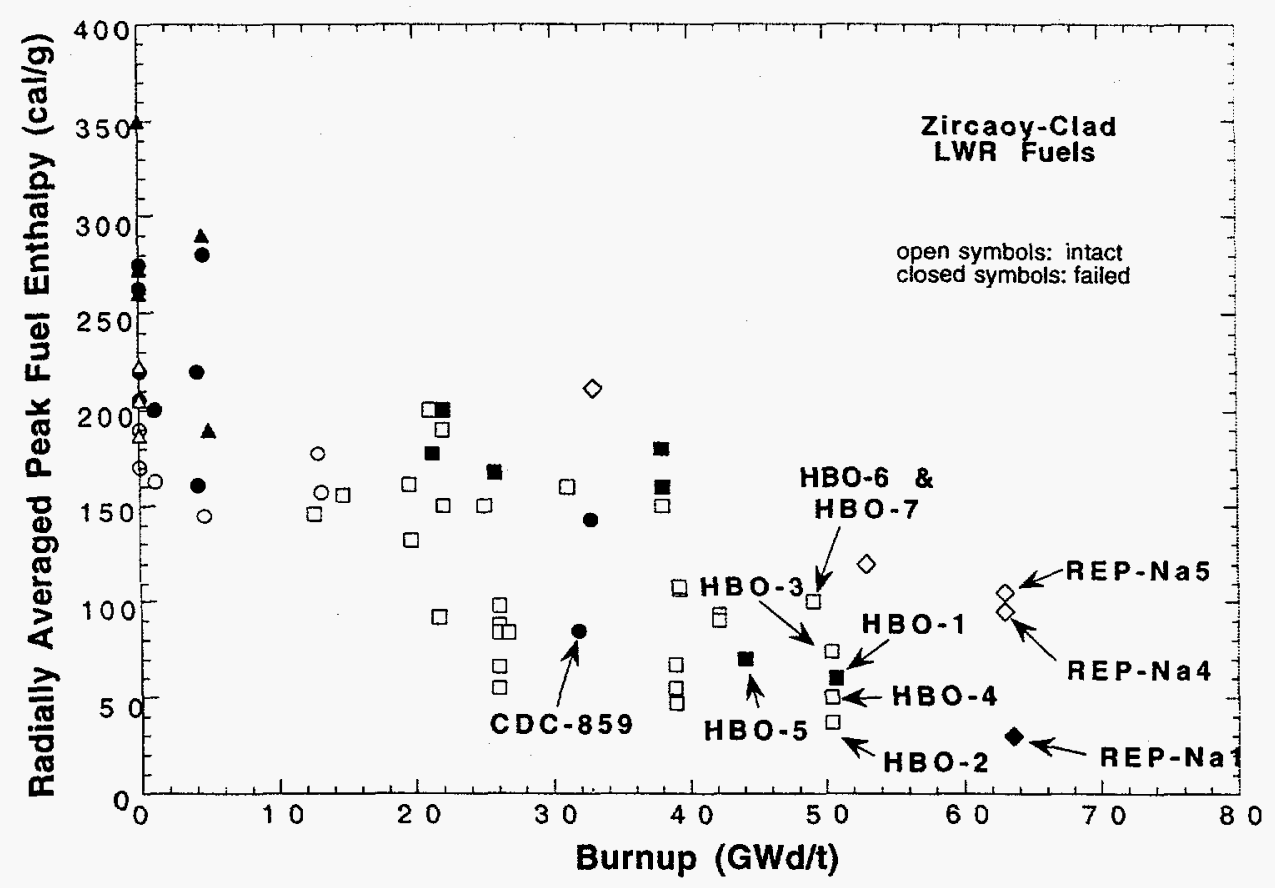

Fig. 1. Peak Fuel Enthalpy vs. Burnup from Simulated Pulse Tests.

Some high-burnup fuels tested were subjected to loading-following operation. ${ }^{2}$ Because of wide variations in metallurgical and the simulation-test conditions, it has been difficult to define a clear-cut failure boundary in terms of the traditional correlation between peak fuel enthalpy at failure and burnup. Under the same test conditions, a cladding specimen sectioned from the same rod failed in one test but survived in the next test, depending on the axial location of the specimen in the fuel rod. Likewise, a specimen from the same grid span failed or survived depending on pulse shape and temperature. Thus, it has been difficult to understand the data base and extract the information needed to understand the failure mechanism and evaluate the performance of high-burnup fuel under an RIA. In this paper, results of simulated tests were analyzed from a new mechanistic understanding of cladding metallurgy, microstructural evolution, and fracture characteristics at high burnup.

\section{EMBRITTLEMENT MECHANISM AT HIGH BURNUP}

As burnup is increased, Zircaloy fuel cladding undergoes several major changes in microstructure and, as a result, mechanical properties are severely degraded. The cladding embrittlement at high burnup has been attributed by many investigators to dense precipitation of "macroscopic" hydrides, which are observed readily by optical microscopy. However, this rather simplified picture seems to have emerged primarily in association with results from the more common axial tensile tests. An axial tension test is relatively easy and convenient to conduct, but the results are not really applicable to RIA situations and could even be misleading, because the effect of the predominantly circumferential hydrides that are characteristic of a highburnup cladding is accentuated unrealistically.

Strong heat-to-heat and reactor-toreactor variations in the ductility of highburnup fuel cladding are quite common, e.g., the tensile properties of the fuel claddings discharged from the Fort Calhoun, 3 Oconee-1,4 ANO-2,5,6 and Calvert Cliffs-16 PWRs. Apparently, the tensile properties of these claddings cannot be explained well on the basis of average hydrogen content only. When the strain data obtained for one batch of cladding from ring-tensile or burst testing are examined, it is quite clear that data 
scattering is significant and that the effect of average hydrogen content is difficult to quantify or not as significant as implied by many investigators. Therefore, it would be helpful to review our present understanding of the embrittlement of Zircaloys at high burnup from the perspective of fundamental mechanisms rather than from the phenomenological point of view.

\section{A. Irradiation Damage}

Irradiation damage in high-burnup cladding is a term commonly used rather loosely to refer to general microstructural features associated with irradiation of one type or the other, which in most cases is damaging to physical and mechanical properties of the material. Damage in Zircaloys irradiated under LWR or CANDU operating conditions is in the form of "black-dot" defects (clusters of irradiationinduced defects), small dislocation loops, short line dislocations, and dislocation entanglements. The latter three types of "damage" in Zircaloys irradiated at $\approx 300^{\circ} \mathrm{C}$ to a relatively low fluence at low burnup is mostly of the "a-type", meaning that the associated Burgers vector is parallel to the "a" axis of the hcp unit cell of the $\alpha$-phase Zircaloy. This is related to the prism slip system of the hcp structure, the only slip system known to be operational under tension.

However, as fluence increases, "ccomponent" dislocation loops and line dislocations emerge in Zircaloys or $\mathrm{Zr}-\mathrm{Nb}$ alloys, ${ }^{7-10}$ meaning that dislocations with a Burgers vector containing the ccomponent (of the hcp unit cell) are produced in increasing numbers. This indicates that in addition to an increasing number density of irradiation-induced defects, a fundamental transition in the nature of irradiation damage occurs from low-burnup to high-burnup operation.

The exact nature of the c-component defects and the mechanism of the transition are, however, not well understood. Nevertheless, the transition, which is characteristic to high-burnup operation, is believed to be a very important process, because onsets of breakaway oxidation, breakaway creep and growth, excessive decrease in ductility, and brittle-type fracture (i.e., pseudocleavage fracture) appear to emerge at about the similar threshold fluence, i.e., $\approx 3 \times 10^{21} \mathrm{n} \mathrm{cm}^{-2}(\mathrm{E}>1 \mathrm{MeV})$. Some reported microstructural features suggest that the c-component dislocations and dislocation loops interact preferentially with oxygen to form precursors of zirconium suboxides. 8 However, the nature of c-component defects and the role of impurities such as oxygen, hydrogen, and iron in the transition from a- to c-component defects are not well understood.

\section{B. Oxide Laver and Oxygen in $\alpha$ Phase}

Water-side oxide layers, in some cases as thick as $80-120 \mu \mathrm{m}$, decrease the remaining thickness of the $\alpha$-phase cladding and increase the number density of radially oriented incipient flaws that facilitate the onset of brittle crack propagation under an RIA. As such, the thickness of the brittle oxide layer itself is a major factor that influences failure behavior. However, the most important factor is the influence of the increased level of oxygen dissolved in the highly irradiated $\alpha$-phase layer, which is the loadbearing material that determines the survivability of the high-burnup cladding under the severe stress of pellet cladding mechanical interaction (PCMI) in RIA situations.

Oxygen in Zircaloys is not an impurity element, but is actually an alloying element added up to 1000-1200 wppm, primarily to increase strength. However, as oxygen content in the $\alpha$-phase layer increases as a function of increasing burnup, and hence, increasing oxide layer thickness, ductility of the load-bearing material decreases significantly. In one case, an oxygen level of $\approx 2330 \mathrm{wppm}$ and hydrogen at $\approx 67 \mathrm{wppm}$ were reported for the mid-wall $\alpha$-phase in a standard Zircaloy -4 fuel cladding irradiated to a burnup of $\approx 28 \mathrm{GWd} / \mathrm{tU}$ in a PWR. 9 Therefore, a significantly higher level of oxygen is expected for high-burnup (e.g., $\approx 60 \mathrm{GWd} / \mathrm{tU}) \alpha$-phase cladding that contains hydrogen at up to several hundred wppm. In particular, the $\alpha$-phase 
layer beneath the thick oxide layer is believed to contain a high level of dissolved oxygen, and hence, will exhibit reduced ductility and fracture toughness.

Several results reported in the literature indicate that a synergism occurs between oxygen solutes dissolved in the load-bearing $\alpha$-phase and irradiationinduced defects. Oi et al. reported that the effect of neutron fluence on irradiation-induced increase in microhardness of $\mathrm{Zr}$ and $\mathrm{Zr}$-base alloys becomes more pronounced with increasing oxygen content in the material. 11 From analysis by the technique of threedimensional dark-field imaging by stereotransmission electron microscopy, irradiation-induced precipitation of zirconium suboxides $\left(\mathrm{Zr}_{3} \mathrm{O}\right)$ and cubic $\mathrm{ZrO}_{2}$ particles of extremely fine scale has been reported for Zircaloy- 2 and -4 fuel cladding irradiated to a fluence of $\approx 4 \times 10^{21} \mathrm{n} \mathrm{cm}^{-2}$ $(\mathrm{E}>0.1 \mathrm{MeV})$, respectively, in a BWR and a PWR.9,10 Consistent with this, occurrence of $\mathrm{ZrO}$ complexes has been reported for unirradiated Zircaloy-4 based on an analysis by atom-probe field ion microscopy. 12 The irradiation-induced oxide precipitates were extremely small $(<10 \mathrm{~nm})$ and very high in number density, particularly in Zircaloy-2 cladding. Because the size and morphology are virtually identical to those of "black-dot" defects, these precipitates can be easily overlooked. Dense precipitation of these ultrafine oxides seems to promote the susceptibility to brittle-type pseudocleavage failure. 9

Tight pellet cladding contact and formation of an oxide layer rich in $\mathrm{Zr}, \mathrm{U}$, and $\mathrm{Pu}$ are frequently observed on the inner-diameter (ID) surface of high-burnup cladding. This will prevent contraction of cladding in the axial direction and tends to increase the axial strain and decrease the circumferential strain under PCMI loading in an RIA. In fact, circumferential expansion produced in high-burnup cladding during RIA-simulated tests in the NSRR and CABRI reactors seems to be always accompanied by axial elongation rather than the contraction normally observed in a burst test. Ductility of axially constraint or axially stretching $\alpha-$ phase cladding tube is significantly lower than that of freely contracting cladding. This peculiar effect is produced as a result of the combination of strong texture and the characteristic slip system, which is limited to prism slip in the $\alpha$-phase cladding,.

\section{Hydride Density and Orientation}

Increased hydriding of the $\alpha$-phase layer is one of the most important metallurgical processes associated with high-burnup operation. Because of the porous and flaky nature of the postbreakaway oxide layer, $\approx 16 \%$ of hydrogen atoms (produced from oxidation) permeate through the oxide layer and end up in the metallic $\alpha$-phase Zircaloy. In contrast, the hydrogen uptake ratio in $\mathrm{Zr}-2.5 \% \mathrm{Nb}$ alloy is only $\approx 5 \%$.

Most of the hydrogen atoms in the high-burnup $\alpha$-phase Zircaloy are contained in the circumferential hydrides, which are in most cases densely concentrated beneath the colder waterside oxide layer. 6 Because oxidation increases almost exponentially as a function of burnup at $>40 \mathrm{GWd} / \mathrm{tU}$, hydrogen uptake, and hence, the volume fraction of the circumferential hydrides beneath the thick oxide layer, increases almost exponentially as burnup increases. These circumferential hydrides are, however, not severely deleterious to mechanical properties as long as the primary stress, as in the case of an RIA, is parallel to the tangential direction of the cladding.

Relatively shorter hydride stringers distributed parallel to the radial direction are most deleterious to cladding mechanical properties. Fortunately, this type of hydride does not seem to be produced in significant number density, at least up to $\approx 50 \mathrm{GWd} / \mathrm{tU}$ for standard Zircaoy-4 cladding (e.g., HBO-1 cladding ${ }^{1}$ in Fig. 1). However, as burnup and oxide layer thickness increase further, the probability of forming radial hydrides becomes increasingly higher, especially in association with pellet cladding interaction, bowing, load-following operation, and use of nonchamfered pellets. Because these factors are also conducive to higher stress on the oxide 
layer, radial hydrides are usually observed in association with a spalled oxide layer that is close to stoichiometry and characteristically whitish in color. The dense radial hydride structure that is characteristic of the REP-Nal ${ }^{2}$ (Fig. 1) appears to be related to load-following operation and significant oxide spallation.

These macroscopic hydrides, either circumferential or radial, are readily resolved by optical microscopy. However, there is, another type of hydride in irradiated Zircaloys, i.e., microscopic hydrides $30-100 \mathrm{~nm}$ in size that can be resolved only by transmission electron microscopy. 9,10 This type of hydride can easily be overlooked when hydride characterization is based only on optical microscopy. Density of the microscopic hydrides, usually precipitated in association with irradiation-induced dislocation loops and line dislocations, increases with increasing burnup.

Both types of hydrides play an important role in degrading the mechanical properties of high-burnup fuel. However, it is important to recognize that hydride morphology, orientation, and density are the real factors that influence the mechanical properties of high-burnup cladding rather than the hydrogen content itself. The effect of hydrides has been investigated extensively for $\mathrm{Zr}-2.5 \mathrm{Nb}$ CANDU pressure tube material by the use of a parameter referred to as the "hydride continuity constant" (HCC). 13 The HCC can have a value between 0 and 1 , with a low value corresponding to a situation in which only a few hydrides are present or the hydrides are oriented predominantly in the circumferential direction. A high HCC corresponds to a high density of radially oriented hydrides. Based on a comparison of hydride morphologies with those reported by Wallace et al., 13 HCCs from optical photomicrographs of $\mathrm{HBO}-1^{1}$ and $\mathrm{REP}-\mathrm{Na} 1^{2}$ are estimated to be 0 and $\approx 0.2$, respectively. When hydrogen content is very high, number densities of both total and radial hydrides should of course increase correspondingly, and hence $\mathrm{HCC}$ will increase.

Bai et al. reported that roomtemperature tensile elongation and reduction in area of unirradiated Zircaloy-4 decrease abruptly for $\mathrm{H}>\approx 700$ wppm. 14 This indicates that total hydride density and fraction of radial hydrides increase rapidly for $\mathrm{H}>\approx 700 \mathrm{wppm}$. In contrast, at $350^{\circ} \mathrm{C}$, tensile ductility remained more or less independent of hydrogen content up to $\approx 1100 \mathrm{wppm}$, indicating that hydrides at $\approx 350^{\circ} \mathrm{C}$ are ductile. This shows that cladding ductility is a strong function of not only HCC but also temperature.

The result of Bai et al. also shows that heavily hydrided unirradiated Zircaloy4 (e.g., $\mathrm{H}>\approx 700$ wppm) undergoes ductilebrittle transition (DBT) between room temperature and $350^{\circ} \mathrm{C}$. Ductile-brittle transition behavior has been investigated extensively by investigators in the CANDU reactor community for unirradiated $\mathrm{Zr}$ $2.5 \mathrm{Nb}$ (e.g., see Refs. 13 and 15). The result of $\mathrm{Bai}$ et al. is in fact an independent confirmation of the DBT phenomenon for hydrided Zircaloy-4. For unirradiated $\mathrm{Zr}-2.5 \mathrm{Nb}$, Davies and Stearns reported that ductile-brittle transition temperature (DBTT) was in the range of $175-280^{\circ} \mathrm{C}$, depending on $\mathrm{HCC}$ (with a hydrogen content of 30-100 wppm). 15 They showed that fracture toughness $(\approx 150 \mathrm{MPa}$ $\mathrm{m}^{0.5}$ ) of the hydrided alloy at $175-240^{\circ} \mathrm{C}$ was nearly independent of $\mathrm{HCC}$ for $\mathrm{HCC}<$ $\approx 0.55$ and then abruptly decreased at higher $\mathrm{HCC}$. At $25^{\circ} \mathrm{C}$, fracture toughness decreased gradually from $\approx 150 \mathrm{MPa} \mathrm{m}^{0.5}$ to $\approx 40 \mathrm{MPa} \mathrm{m} 0.5$ as $\mathrm{HCC}$ increased.

Such information appears to be extremely useful in understanding the effects of hydriding in low-energy failure behavior such as that seen in HBO-1, HBO-5, and REP-Na1. For example, from the standpoint of the separate effect of hydriding alone, the results of HBO-1 (HCC $\approx 0$, hydrogen content $\approx 190 \mathrm{wppm}$ ) and HBO-5 tests on Zircaloy-4 PWR fuel appear to be conservative. This is because the effect of hydriding on the ductility and fracture toughness of the specimens at $<50^{\circ} \mathrm{C}$ (i.e., the failure temperature of HBO- 1 and HBO-5) would be more pronounced than at $\approx 270^{\circ} \mathrm{C}$, i.e., the estimated temperature of a PWR hot zeropower rod-ejection accident.

Likewise, from the standpoint of hydriding alone, it is reasonable to postulate that the fracture toughness of the REP-Nal specimen was very low (i.e., 

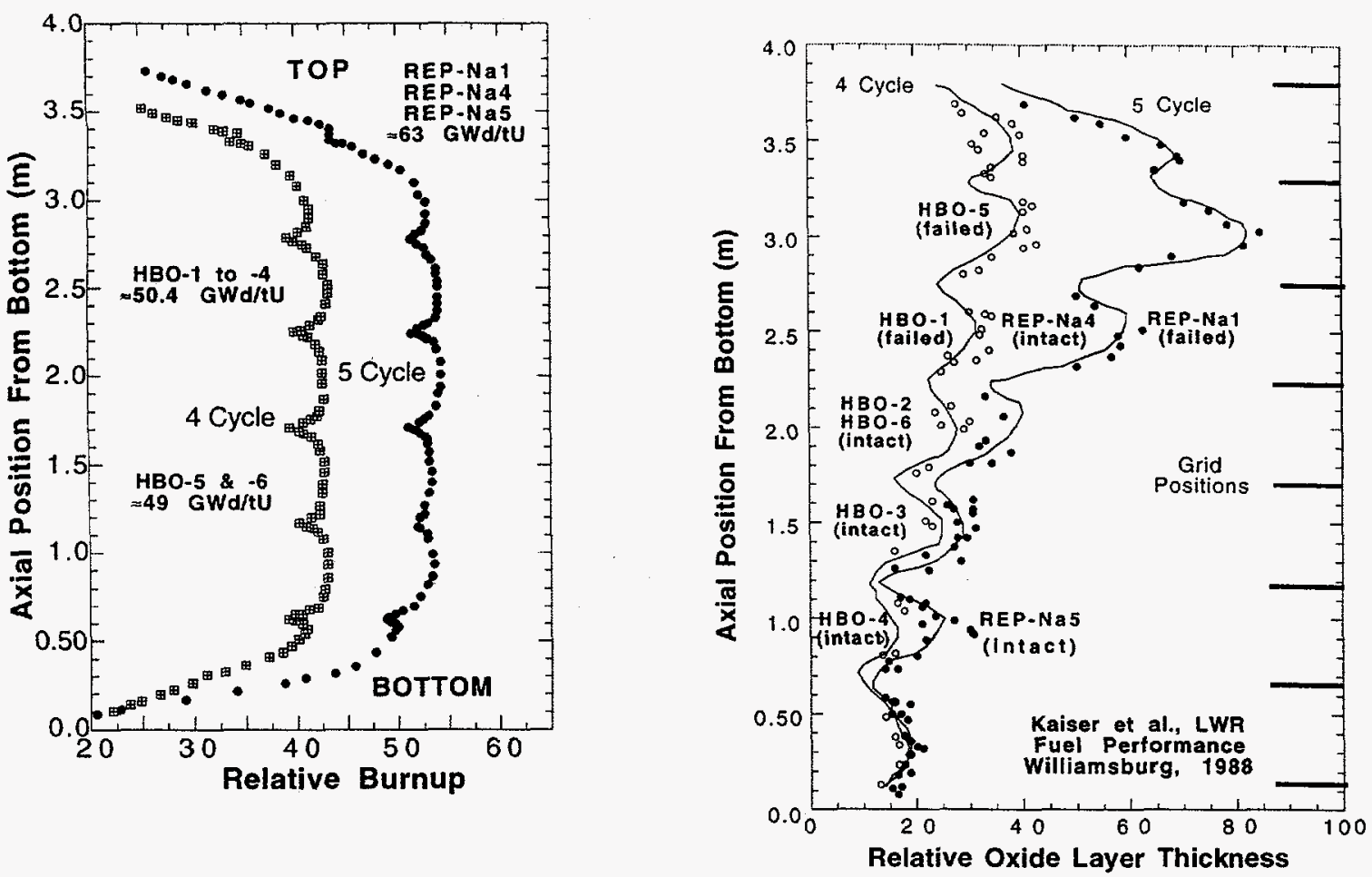

Fig. 2. Correlation of the Relative Susceptibility of High-Burnup PWR Fuel to Failure from Simulated RIA Tests in NSRR and CABRI Reactors with Axial Location and Oxide Layer Thickness of the Cladding.

in the "lower shelf") at the temperature of failure (probably $<330^{\circ} \mathrm{C}$ ), because $\mathrm{HCC}$ $(\approx 0.2)$ as well as hydrogen content $(600-750$ wppm) were rather high in the specimen. This much higher $\mathrm{HCC}$ and hydrogen content are very likely due to a result of the load-following operation or oxide spallation of the high-burnup fuel.

\section{Relative Susceptibility to Failure}

Of the three primary metallurgical processes that cause embrittlement at high burnup, irradiation damage is determined primarily by fast neutron fluence, and hence by fuel burnup. The other two processes (i.e., the effects of oxide layer and oxygen in solution, and hydride density and orientation) are determined primarily by oxidation. Therefore, for a fuel rod of a given irradiation history, degree of embrittlement, and hence susceptibility to failure can be expressed as a first approximation as a function of degree of oxidation (e.g., oxide layer thickness) if test conditions (e.g., temperature and width of pulse) are similar.
Because oxide layer thickness is strongly influenced by the axial position (grid span) in a PWR fuel, relative susceptibility to failure is therefore expected to be strongly influenced by the cladding grid span. This was actually observed in the test series HBO-1 to -4 , which was conducted on specimens sectioned from different grid spans of a same rod; see Fig. 2. Similar correlations are also shown for the test series of HBO5 and -6 and REP-Na 1 and $-\mathrm{Na} 5$. Those specimens from the upper grid spans (where the oxide layer is thickest) are most susceptible to failure, whereas cladding from the lower grid spans are more resistant to failure even though burnup is similar. From the results in Fig. 2 alone, it can therefore be deduced that the conventional parameter of fuel burnup is not suitable for predicting failure behavior of high-burnup fuel.

\section{MECHANICAL PROPERTIES}

\section{A. Tensile Properties}

Cladding failure under RIA situations has been frequently correlated with 
ductility determined from slow uniaxial tensile tests in which a cladding tube was pulled in the axial direction of the cladding. Deformation and fracture behavior from these axial tensile tests are, however, not applicable to RIA situations because of the very different effects of the circumferential hydrides that are dominant in most high-burnup cladding. Because the stress in an axial tensile test is perpendicular to the circumferential hydrides, the damaging effect of hydrides is greatly exacerbated, and as a result, measured ductility is strongly influenced by hydrogen content even though $\mathrm{HCC}$ is low.

In comparison, results from ring tensile or burst tests are more applicable, because the effect of hydride orientation is more typical of that in an RIA. However, failure strains determined from an "unmodified" ring tensile test is in some cases somewhat ambiguous, because "gage" section is not clearly defined and the effect of bending moment is significant.

In contrast to results from axial tensile tests, ductility determined on the same batch of high-burnup fuel rods from ring tensile or burst tests exhibits large data scattering and less significant effects of hydrogen content. ${ }^{3-6}$

\section{B. Burst Test}

In an internal-gas-pressurization burst test, biaxial ratio (i.e., hoop-to-axial stress ratio) is 2 , and the tube specimen is free to contract axially and relatively more susceptible to necking instability. As a result, a burst in the $\alpha$-phase-temperature region (i.e., $\quad<815^{\circ} \mathrm{C}$ ) is usually accompanied by some degree of axial contraction in commercial fuel cladding. This is related to the texture of the $\alpha$ phase cladding in which the operational slip system is limited to prism slip. Because of the axial contraction, circumferential strain at failure tends to be relatively large.

In contrast to this, a high-burnup cladding subjected to PCMI loading under RIA situations is characterized by lower biaxiality, relatively higher resistance to necking, and significant axial elongation.

\section{Effect of Strain Rate}

Based on posttesting measurement of the circumferences of the cross sections, the maximum failure circumferential strain of the $\mathrm{HBO}-1$ specimen was $\approx 4.4 \%$. Considering the half-pulse width of $\approx 4.5$ ms or the rod-pressure vs. time record, 1 this corresponds to a strain rate of $\approx 10 \mathrm{~s}^{-1}$ and an effective deformation velocity of $\approx 0.3-0.4 \mathrm{~m} / \mathrm{s}$. For extremely high deformation velocity, necking has been known to be suppressed because of inertial effect, which leads to a higher ductility. ${ }^{16}$ According to a model reported by Altynova et al., this effect is predicted to be significant for $\mathrm{Al}$ and $\mathrm{Cu}$ alloys when deformation velocity exceeds $\approx 0.4 \mathrm{~m} / \mathrm{s}$. It is not clear if this effect was significant for the unirradiated or irradiated Zircaloy cladding specimens that were tested in the NSRR, CABRI, PBF, or SPERT reactors, or is expected to be significant under RIA situations. At any rate, the effect of extremely high strain rate on the deformation behavior of Zircaloys is not well understood at present, and wellcontrolled tests seem to be warranted to clarify the strain rate effect.

\section{Fracture Toughness}

The most important mechanical property in RIA situations is the dynamic fracture toughness of the high-burnup cladding, a material composed of a thick oxide layer, $\alpha$-phase Zircaloy -4 , and thin fibres of hydrides that are oriented mostly parallel to the circumferential direction of the cladding tube. In fresh unirradiated state, when oxide thickness and hydride volume fraction are negligible, fracture toughness of the material is high regardless of temperature, and failure is governed by the onset of ductile plastic instability.

However, in the highly irradiated, oxygenated, and hydrided state, the fracture toughness of $\alpha$-phase Zircaloys is sensitive to temperature and exhibits DBT phenomena similar to those of bcc metals. Compared to the studies on unirradiated hydrided materials, investigation of DBT phenomenon in irradiated $\mathrm{Zr}$-base alloys has been very limited. Based on $J-R$ fracture toughness testing, DBTTs up to $\approx 280^{\circ} \mathrm{C}$ have been reported for Zircaloy-2 


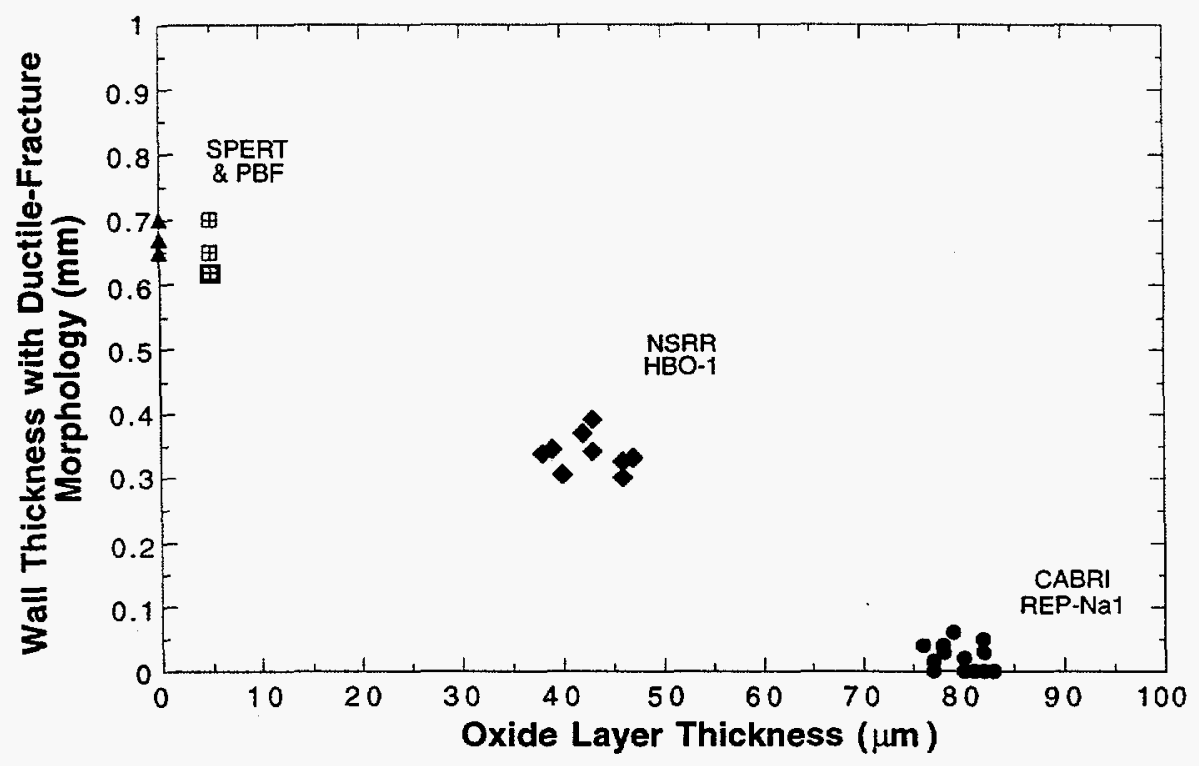

Fig. 3. Wall Thickness with Ductile Fracture Morphology vs. Average Oxide Layer Thickness, Showing Increasing Susceptibility to Brittle Crack for Increasing Oxidation.

CANDU reactor pressure tubes. 17,18 Results from similar investigations on the DBT phenomenon have been reported for $\mathrm{Zr}-2.5 \% \mathrm{Nb}$ pressure tubes (irradiated at $\approx 300^{\circ} \mathrm{C}$ in CANDU reactors). ${ }^{18,19}$ Based on this information, DBTT of some highburnup Zircaloy-4 cladding such as the well-known specimens of the REP-Na1 and HBO-1 tests is expected to be significantly high, probably close to or even higher than $250^{\circ} \mathrm{C}$.

\section{ANALYSIS OF FAILURES AT LOW- ENERGY DEPOSIT}

\section{A. Fracture Characteristics}

Results from optical metallography of the fracture tips of the low-energy failures (such as HBO-1 and REP-NaI) indicate that some failures were predominantly brittle cracking, whereas the others can be classified as partially brittle and partially ductile cracking. Observed fracture tip morphologies can be classified as the following:

Type O Brittle crack across OD oxide.

Type $\mathrm{H}$ Brittle crack through a large localized hydride blister or sunburst.
Type B Brittle crack across the oxygenand hydride-rich layer beneath the thick oxide layer.

Type $\mathrm{CH}$ Brittle crack along the long circumferential hydrides.

Type BM Brittle crack in metal nearly parallel to radial direction.

Type D Ductile shear of $\alpha$-phase layer characterized by $\approx 45^{\circ}$ angle of propagation.

Susceptibility to failure of a highburnup PWR fuel seems to be determined primarily by Types $\mathrm{O}, \mathrm{B}$, and $\mathrm{BM}$ cracking. Failure of some fuels, such as those irradiated in helium in JMTR, has been known to be associated with Type $H$ cracks. Interestingly, a direct evidence of Type $\mathrm{H}$ crack was not observed for REPNa1. To better quantify the degree of brittle cracking, portions of ductile and brittle crack propagation were measured in the fracture tips from cross-section photomicrographs, and crack tip wall thickness with ductile-fracture morphology is plotted as a function of average oxide layer thickness of the section; see Fig. 3. The figure clearly demonstrates that susceptibility to brittle failure increases 


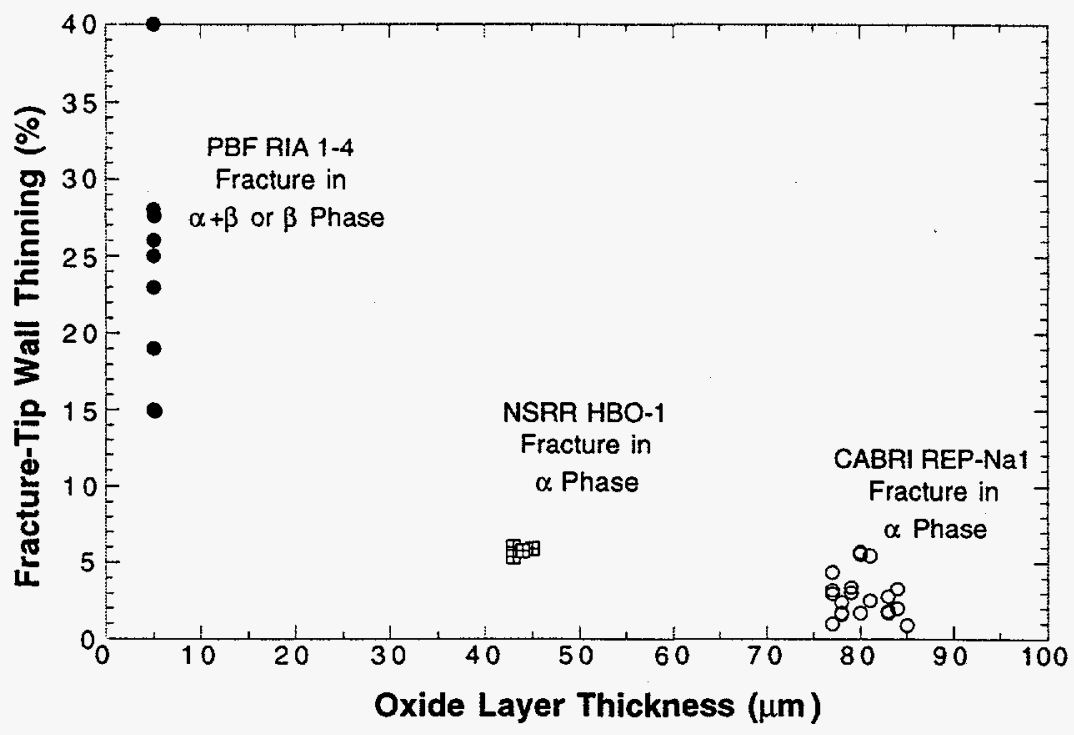

Fig. 4.

Fracture Tip Wall Thinning vs. Average Oxide Layer Thickness, Showing Little Wall Thinning at High Oxidation.

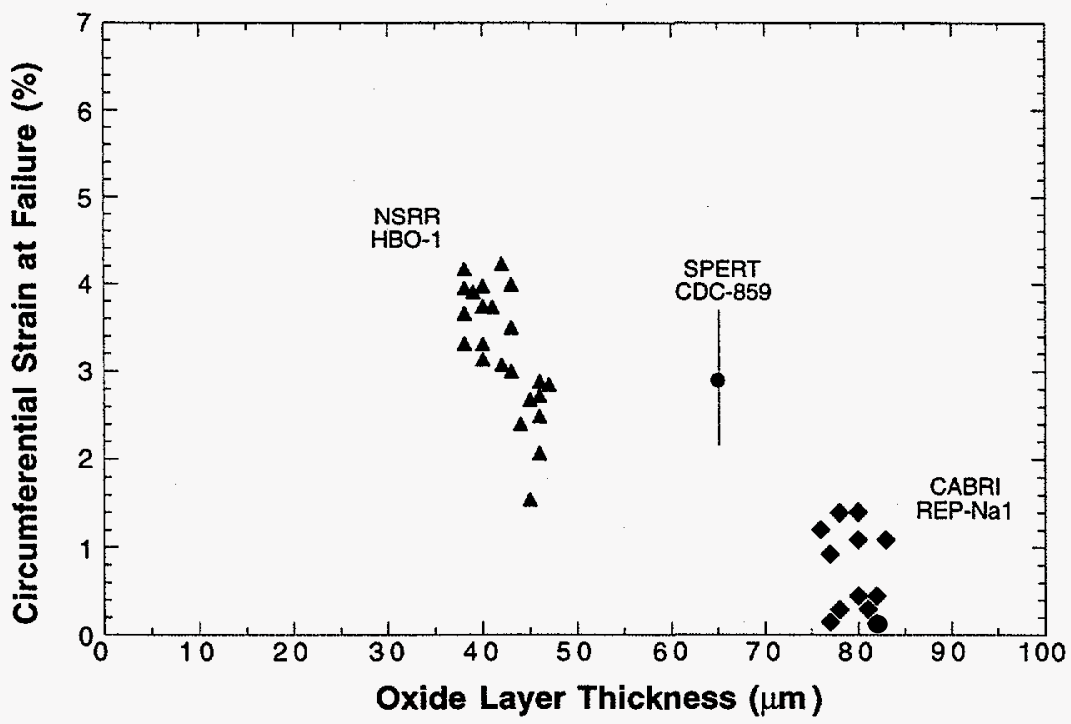

Fig. 5.

Circumferential Failure Strain us. Average Oxide Layer Thickness, Showing Brittle Nature of REP-Na1 Failure.

significantly as local oxide layer thickness increases.

The relative degrees of ductile and brittle nature of HBO-1 and REP-NaI are also manifested by the degree of wall thinning and circumferential strain at failure (see Figs. 4 and 5). From Figs. 3-5, we can deduce that REP-Nal failure is essentially brittle, whereas $\mathrm{HBO}-1$ failure was partially brittle.

\section{B. Failure Model}

Based on the results of Figs. 3-5 and other available information on post-test microstructural features, 1,2 a model of fracture sequence is shown schematically for HBO-1 and REP-Na1, respectively, in Figs. 6 and 7 .

As shown in the figures, incipient cracks were observed only on the outer surface in the HBO-1 specimen, indicating that the through-wall crack propagated from the outer surface to the inner surface of the wall. That is, the crack could not have nulceated in the ductile inner side. In contrast to this, incipient partial cracks were observed on both outer and inner surfaces in REP-Na1, indicating that the entire wall was so brittle that cracks could nucleate on both sides. Under such conditions, the role of hydride blisters and Type $H$ cracking would have been secondary. 

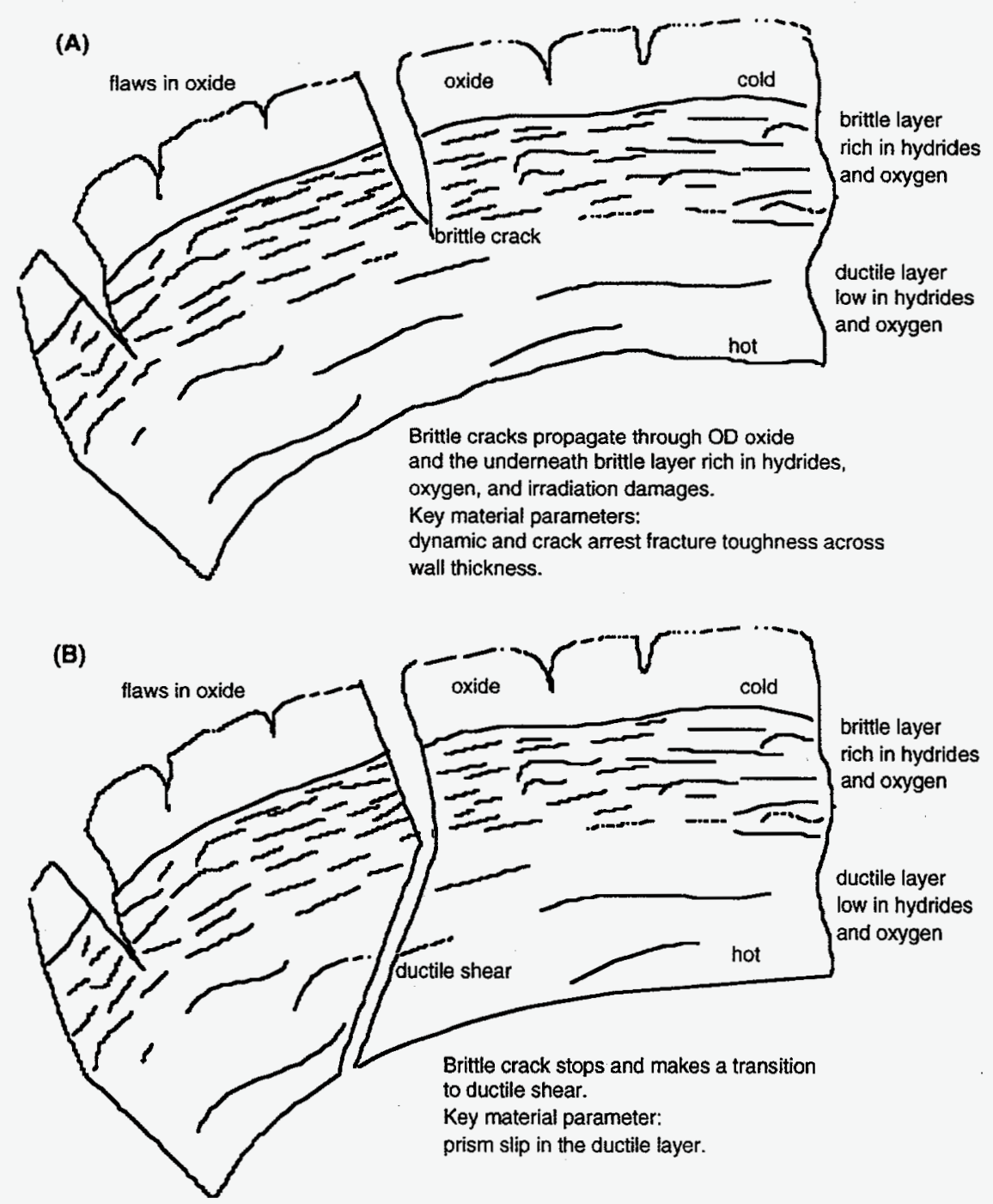

Key material parameters: dynamic and crack-arrest fracture toughness
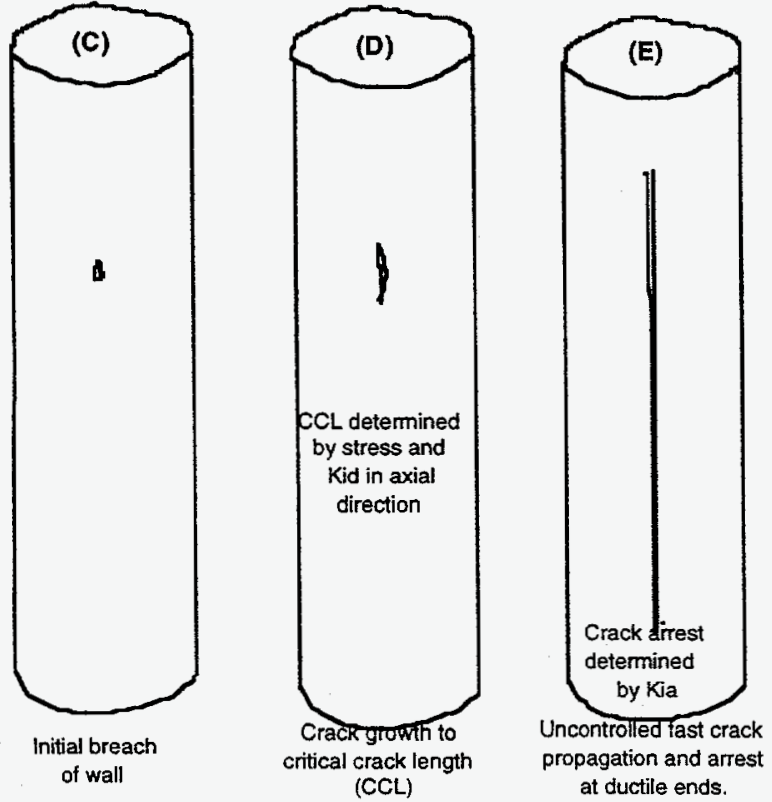

Fig. 6.

Schematic Illustration of Microstructure, Sequence of Failure, and Key Material Parameters Modeled for HBO-1; (A) and (B) Initial Through-Wall Crack Propagation; (C) to (E) Subsequent Axial Crack Propagation. 


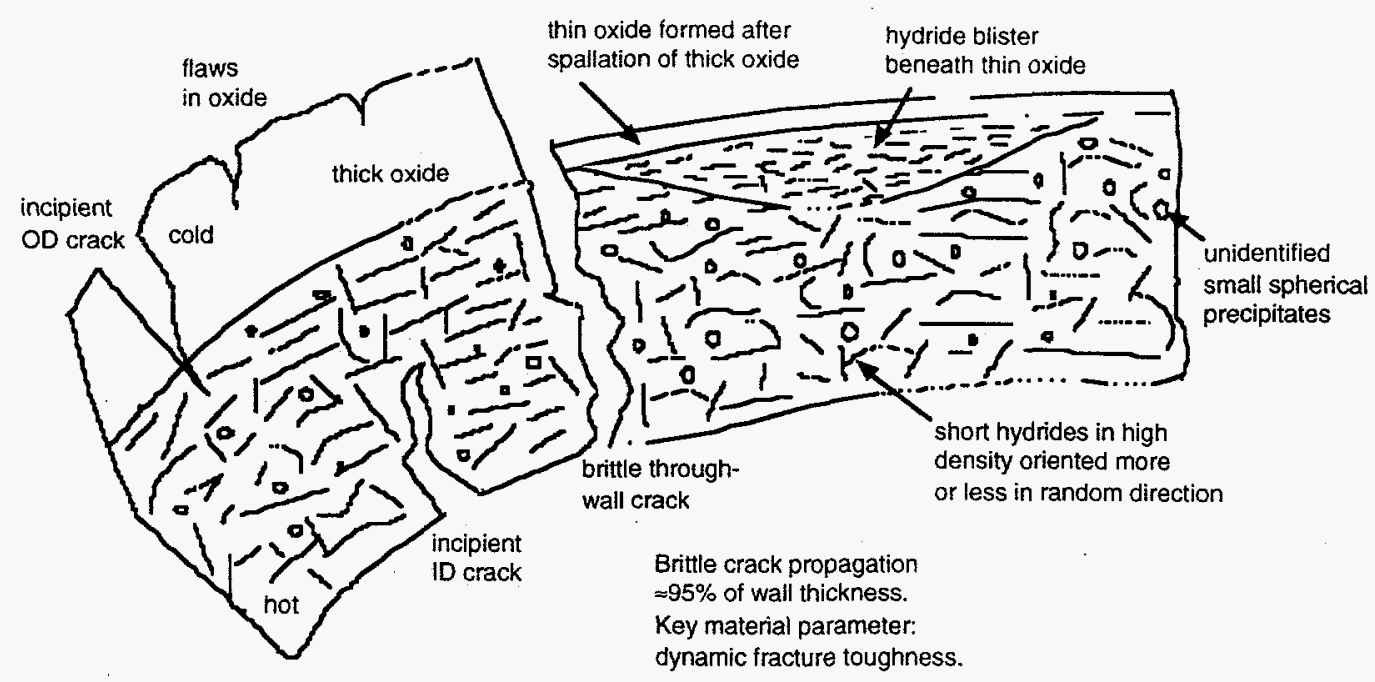

Fig. 7. Schematic Illustration of Microstructure, Sequence of Failure, and Key Material Parameters Modeled for Initial Through-Wall Cracking in Rep-Na1. Axial cracking sequence is believed to be similar to that of HBO-1 depicted in Fig. 6.

It is also important to note that the sequence of long axial cracking, illustrated schematically in Figs. 6C-6E, can be explained only by assuming a brittle-type crack propagation in association with low dynamic fracture toughness in the axial direction. From standpoint of practical safety concern on possible fuel dispersal, this type of long axial cracking appears to be of primary importance.

In the model schematically illustrated in Figs. 6 and 7 , numerous cracks are nucleated in the brittle layer (preferentially at the outer-surface oxide layer), which is not sensitive to pulse temperature. Many of the incipient cracks propagate through the oxygen- and hydride-rich brittle $\alpha$-phase layer beneath the OD oxide, some propagating eventually through the entire wall thickness, either in ductile or brittle manner, depending on the microstructure and fracture toughness of the metallic phase. One or more of these through-wall cracks then reaches critical length and propagates axially in an uncontrolled manner, producing one or more long axial splits.

\section{Effects of Pulse Width and Pulse Temperature}

Based on the information on DBT phenomena in irradiated and unirradiated heavily hydrided $\mathrm{Zr}$-base alloys (which was discussed above in terms of fracture toughness and ductility), the DBTT of high-burnup Zircaloy-4 cladding such as REP-Na1 and HBO-1 is believed to be significantly high. Failure of such cladding is predicted to be sensitive to initial pulse temperature and pulse width. This is illustrated schematically in Fig. 8.

According to the model in Fig. 8, crack propagation in the radial and axial directions through the $\alpha$-phase layer is sensitive to pulse temperature relative to the DBTT of the local material. That is, depending on whether the dynamic fracture toughness of the metallic phase is at the upper shelf or lower shelf, resistance to crack propagation, and hence failure, will be very different. For example, if the DBTT of the metallic phase is $\approx 250^{\circ} \mathrm{C}$ and the cladding is pulsed at $25^{\circ} \mathrm{C}$ at a high rate (e.g., pulse width of $\approx 5 \mathrm{~ms}$ ), then susceptibility to failure would be high because fracture toughness at the time of peak stress is low (in the lower-shelf). In contrast, if the cladding is pulsed at $\approx 300^{\circ} \mathrm{C}$ at a slow rate (e.g., pulse width of $\approx 70 \mathrm{~ms}$ ), susceptibility to failure would be relatively low because the fracture toughness is high (in the upper-shelf). 

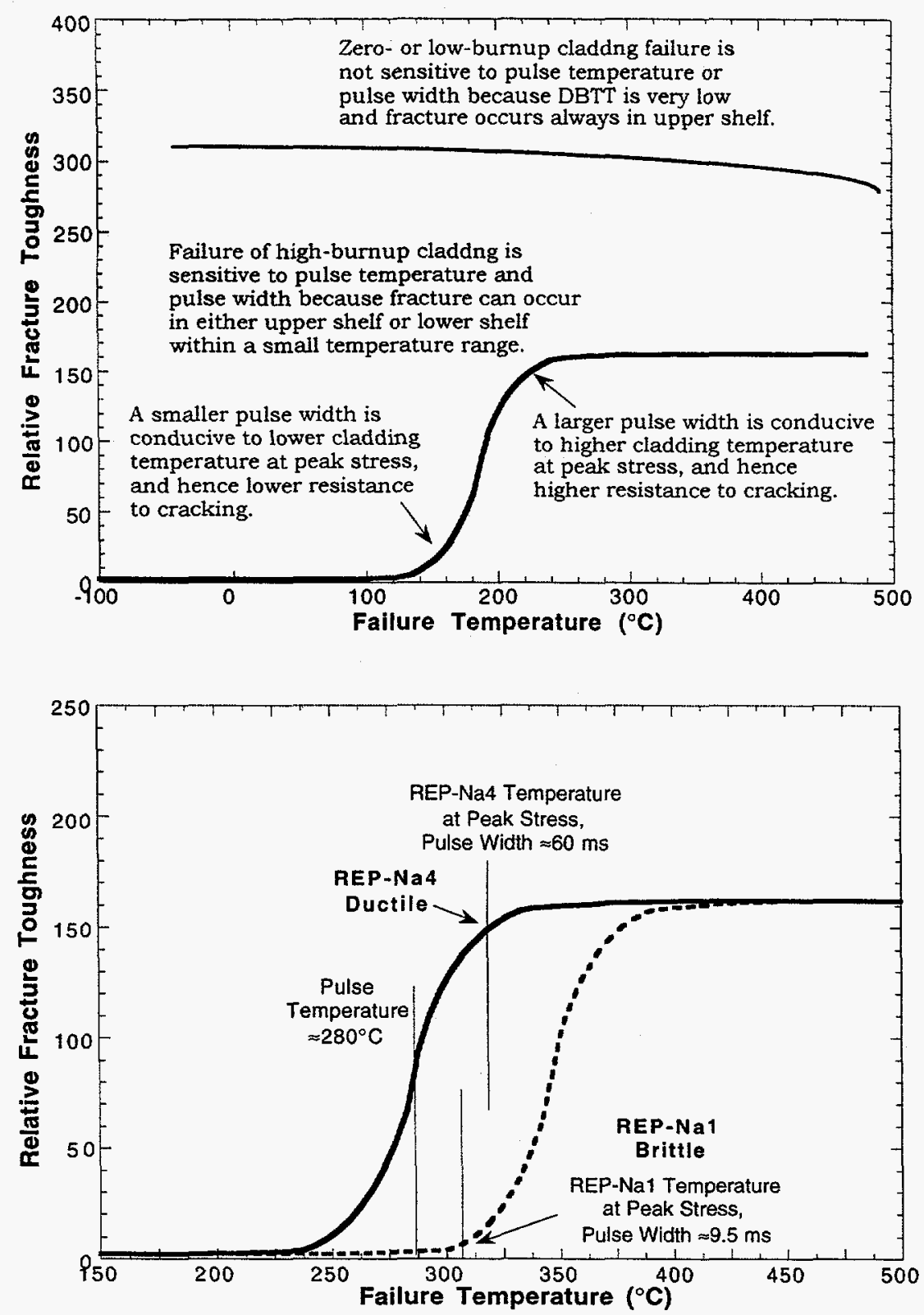

Fig. 8.

Schematic Illustration of Sensitivity of HighBurnup Fuel Cladding Failure to Initial Pulse Temperature and Pulse Width in Terms of Fracture Toughness us. Temperature.

Fig. 9.

\section{Schematic Illustration of a Model Based on Temperature-Sensitive Fracture Toughness to Explain the Relative Failure Behavior of Rep- $\mathrm{NaI}$ and-Na4.}

The model also predicts a strong effect of pulse width when the initial pulse temperature is in transition range, i.e., lower than and close to the DBTT of the remaining metallic phase. This effect of pulse rate, predicted to be unique to highburnup fuel cladding, will not be significant for unirradiated or low-burnup cladding, because the DBTT of such material will be significantly lower than the temperature relevant to an RIA.

According to the model, the failure behavior of REP-Na1 and - Na4 can be also explained as shown in Fig. 9. A small difference in DBTT of the two specimens, combined with the difference in pulse width $(\approx 9.5$ and $\approx 60 \mathrm{~ms}$ for REP-Na 1 and REP-Na4, respectively) ${ }^{2}$, could likely have resulted in a situation in which REP-Na4 is stressed at the upper shelf, (hence no failure), whereas REP-Nal was stressed at the lower shelf, (hence failure).

\section{Threshold Failure Energy}

On the basis of the embrittlement mechanisms, DBT phenomena, and failure 


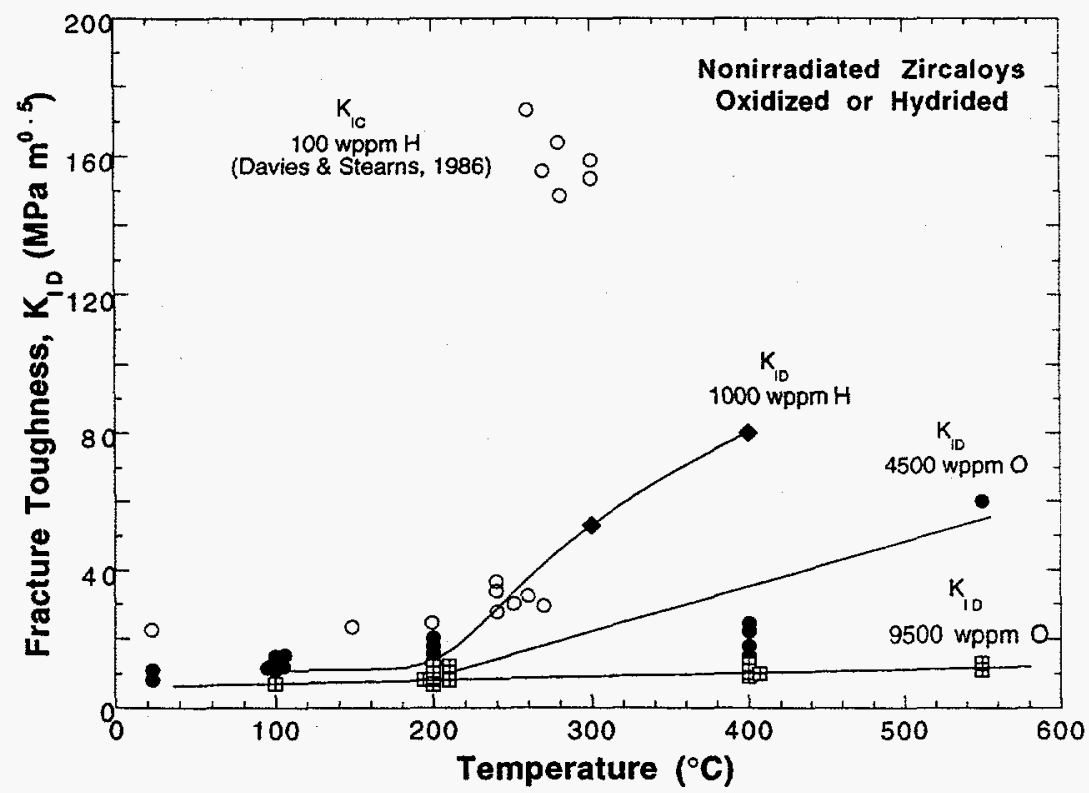

Fig. 10.

\section{Dynamic Fracture} Toughness of Unirradiated Zircaloys as Function of Hydrogen and Oxygen Content and Temperature, from Ref. 20. $K_{I C}$ data from Ref. 13 are also shown for . .comparison.

characteristics analyzed above, the threshold failure energy can be expresssed by an equation based on cladding microstructural parameters as following:

$$
E=f_{1}\left(X_{O H}\right) f_{2}\left(C_{O}, C_{H}, H C C, T\right) \text {, }
$$

where $E$ is the threshold failure energy. The function $f_{1}$ represents the direct effect of the brittle oxide layer or hydride blister which reduces the thickness of the loadbearing $\alpha$-phase layer, whereas $f_{2}$ is a function that represents the degree of embrittlement of the $\alpha$-phase layer itself. $\mathrm{X}_{\mathrm{OH}}$ is the thickness of the oxide layer or hydride blister; $\mathrm{C}_{O}$ is the average oxygen content in the $\alpha$-phase layer; $\mathrm{C}_{\mathrm{H}}$ average hydrogen content in the $\alpha$-phase layer; HCC hydride continuity constant, and $T$ is the cladding temperature at peak stress. The function $f_{1}$ can be expressed by a relatively simple equation:

$$
\mathrm{f}_{1}=\mathrm{E}_{\mathrm{O}}-\mathrm{k} \mathrm{X}_{\mathrm{OH}},
$$

where $\mathrm{E}_{0}$ and $\mathrm{k}$ are constants.

For unirradiated or low-burnup cladding, the function $f_{2}$ is essentially unity. For high-burnup cladding, $f_{2}$ is between 0 and 1 ; it decreases with increasing $\mathrm{CO}_{\mathrm{O}} \mathrm{C}_{\mathrm{H}}$, and $\mathrm{HCC}$ and increases with temperature. Qualitatively, the shape of $f_{2}$ will be similar to those of the fracture toughness functions $13,15,17-20$ (see Fig. 10 as an example) or the ductility function shown in Fig. 91 in Ref. 21. However, quantitative data base and information that allow construction of $f_{2}$ function applicable to RIA situations are not available yet.

\section{v. CONCLUSIONS}

1. Primary factors for embrittlement of high-burnup cladding are neutron damage, thick oxide layer, higher oxygen level in solution, hydride density, and radial orientation of hydrides in the $\alpha$-phase material.

2. These embrittlement processes are most strongly influenced by oxidation. Therefore, failure behavior can be correlated well with oxide layer thickness, which is strongly influenced by axial position (grid span). Fracture properties, such as circumferential strain, wall thinning, and degree of brittle fracture-tip morphology, could be correlated well with outer-surface oxide layer thickness.

3. Fracture behavior in low-energy failures such as those of HBO-1, and REP-Na1, and REP-Na4 can be explained well by a model based on fracture toughness that is sensitive to temperature and microstructure. The long axial splits that are characteristic of low-energy failures can be explained only on the 
basis of fast brittle crack propagation in the axial direction.

4. Failure of high-burnup cladding is predicted to be sensitive to initial pulse temperature and pulse width if the pulse temperature is close to the ductile-brittle transition temperature of the material. This effect is unique to high-burnup fuel cladding.

5. A new approach based on two mechanistic functions is proposed for prediction of failure threshold energy. The first function represents the direct effect of the brittle oxide layer or hydride blisters. The second function, which represents the degree of embrittlement of the remaining $\alpha$-phase layer, is based on microstructural and fracture-toughness properties that are characteristic of the $\alpha$-phase layer at high-burnup.

\section{ACKNOWLEDGMENTS}

The authors thank R. O. Meyer and H. $H$. Scott for helpful discussions, and F. Schmitz and T. Fuketa for providing many helpful materials and metallographs.

\section{REFERENCE}

1. K. Ishijima and T. Fukeda, "Progress of the RIA Experiments with High Burnup Fuels and Their Evaluation in JAERI," Proc. 24th Water Reactor Safety Information Mtg., Oct. 21-23, 1996, Bethesda, MD, in press.

2. F. Schmitz, Ch. Gonnier, and J. Papin, "The Status of the CABRI TEST Program: Recent Results and Future Activities," Proc. 24th Water Reactor Safety Information Mtg., Oct. 21-23, 1996, Bethesda, MD, in press.

3. A. M. Garde, "Hot Cell Examination of Extended Burnup Fuel from Fort Calhoun," DOE/ET/34030-11, CEND427, Combustion Engineering, 1986.

4. L. W. Newman, "The Hot Cell Examination of Oconee- 1 Fuel Rods after Five Cycles of Irradiation," DOE/ET/34212-50, BAW-1874, Babcock \& Wilcox, 1986.
5. G. P. Smith, Jr., R. C. Pirek, H. R. Freeburn, and D. Schrire, "The Examination and Demonstration of Methods for Improved Nuclear Fuel Utilization," DOE/ET/34013-15, CEND432, ABB Combustion Engineering, 1994.

6. A. M. Garde, G. P. Smith, and R. C. Pirek, "Effects of Hydrides Precipitate Localization and Neutron Fluence on the Ductility of Irradiated Zircaloy-4," Zirconium in the Nuclear Industry: 11th Intl. Symp., ASTM STP 1295, G. P. Sabol, ed., American Society for Testing and Materials, Philadelphia, 1996, pp. 407-429.

7. R. A. Holt and R. W. Gilbert, " $<\mathrm{c}>$ Component Dislocations in Annealed Zircaloy Irradiated at About $570 \mathrm{~K}, " J$. Nucl. Mater. 137 (1986), p. 185.

8. M. Griffiths and R. W. Gilbert, "The Formation of c-Component Defects in Zr-Alloys during Neutron Irradiation," J. Nucl. Mater. 150 (1987), p. 169.

9. H. M. Chung, F. L. Yaggee, and T. F. Kassner, "Fracture Behavior and Microstructural Characteristics of Irradiated Zircaloy Cladding," Zirconium in the Nuclear Industry: 7th Intl. Symp., ASTM STP 939, R. B. Adamson and L. F. P. Van Swam, eds., American Society for Testing and Materials, Philadelphia, 1987, pp. 775-801.

10. H. M. Chung, "Phase Transformations in Neutron-Irradiated Zircaloys, Radiation-Induced Changes in Microstructure: 13th Intl. Symp., ASTM STP 955, F. A. Garner, N. H. Packan, and A. S. Kumar, eds., American Society for Testing and Materials, Philadelphia, 1987, pp. 676-699.

11. N. Oi, H. Maki, and M. Nomura, "BWR Fuel Performance and Recent Trend of R\&D in Japan," Proc. Intl. Topical Mtg. on LWR Fuel Performance, Williamsburg, VA, April 17-20, 1988, American Nuclear Society, La Grange Park, IL, 1988, pp. 21-30.

12. B. Wadman and H.-O. Andren, "Direct Measurement of Matrix Composition in Zircaloy -4 by Atom Probe 
Microanalysis," Zirconium in the Nuclear Industry: 8th Intl Symp., ASTM STP 1023, L. F. P. Van Swam and C. M. Eucken, eds., American Society for Testing and Materials, Philadelphia, 1989, pp. 423-434.

13. A. C. Wallace, G. K. Shek, and O. E. Lepik, "Effects of Hydride Morphology on $\mathrm{Zr}-2.5 \mathrm{Nb}$ Fracture Toughness," Zirconium in the Nuclear Industry: 8th Intl Symp., ASTM STP 1023, L. F. P. Van Swam and C. M. Eucken, eds., American Society for Testing and Materials, Philadelphia, 1989, pp. 6688.

14. J. Bai, C. Prioul, J. Pelchat, and F. Barcelo, "Effects of Hydrides on the Ductile Brittle Transition in StressRelieved, Recrystallized, and $\beta$-Treated Zircaloy-4," Proc. Intl. Topical Mtg. on LWR Fuel Performance, Avignon, France, 1991, American Nuclear Society, La Grange Park, IL, 1991, pp. 233-251.

15. P. H. Davies and C. P. Stearns, "Fracture Toughness Testing of Zircaloy-2 Pressure Tube Material with Radial Hydrides Using Direct Current Potential Drop," Fracture Mechanics: 17th Volume, ASTM STP 905, J. H. Underwood, R. Chait, C. W. Smith, D. P. Wilhelm, and J. C. Newman, eds., American Society for Testing and Materials, Philadelphia, 1986, pp. 379400 .

16. M. Altynova, X. Hu, and G. Daehn, "Increased Ductility in High Velocity Electromagnetic Ring Expansion," Metallurgical and Materials Trans. A, 27A (1996), pp. 1837-1844.

17. C. E. Coleman, B. A. Cheadle, A. R. Causey, P. C. K. Chow, P. H. Davies, M. D. McManus, D. K. Rogers, S. Sagat, and G. van Drunen, "Evaluation of Zircaloy-2 Pressure Tube from NPD," Zirconium in the Nuclear Industry: 8th Intl Symp., ASTM STP 1023, L. F. P. Van Swam and C. M. Eucken, eds., American Society for Testing and Materials, Philadelphia, 1989, pp. 3549.

18. L. A. Simpson and C. K. Chow, "Effect of Metallurgical Variables and
Temperature on the Fracture Toughness of Zirconium Alloy Pressure Tubes," Zirconium in the Nuclear Industry: 7th Intl Symp., ASTM STP 939, R. B. Adamson and L. F. P. Van Swam, eds., American Society for Testing and Materials, Philadelphia, 1987, pp. 579596.

19. C. K. Chow, C. E. Coleman, R. R. Hosbons, P. H. Davies, M. Griffiths, and R. Choubey, "Fracture Toughness of Irradiated $\mathrm{Zr}-2.5 \mathrm{Nb}$ Pressure Tubes from CANDU Reactors," Zirconium in the Nuclear Industry: 9th Intl Symp., ASTM STP 1132 , C. M. Eucken and A. M. Garde, eds., American Society for Testing and Materials, Philadelphia, 1991, pp. 246-275.

20. A. M. Garde and T. F. Kassner, "Instrumented Impact Properties of Zircaloy-Oxygen and Zircaloy-Hydrogen Alloys," NUREG/CR-1408, ANL-80-14, Argonne National Laboratory, 1980.

21. H. M. Chung and T. F. Kassner, "Embrittlement Criteria for Zircaloy Fuel Cladding Applicable to Accident Situations in Light-Water Reactors: Summary Report," NUREG/CR-1344, ANL-79-48, Argonne National Laboratory, 1980. 